EGU2020-18598

https://doi.org/10.5194/egusphere-egu2020-18598

EGU General Assembly 2020

(c) Author(s) 2020. This work is distributed under

the Creative Commons Attribution 4.0 License.

\title{
Design storm estimation in Tuscany (Italy) through regional frequency analysis and generalized additive modelling
}

\author{
Matteo Pampaloni ${ }^{1}$, Virginia Vannacci ${ }^{2}$, Enrica Caporali ${ }^{1}$, Chiara Bocci ${ }^{2}$, Valentina Chiarello ${ }^{1}$, and \\ Alessandra Petrucci ${ }^{2}$ \\ ${ }^{1}$ Department of Civil and Environmental Engineering, University of Florence, Italy (matteo.pampaloni@unifi.it) \\ ${ }^{2}$ Department of Statistics, University of Florence, Italy (chiara.bocci@unifi.it)
}

In the field of extreme hydrological events, design storm identification represents key element due to the links with flood risk as well as water resources availability and management.

In order to obtain a regional frequency analysis for studying and understanding the annual maximum of daily rainfall, two different statistic methods are proposed here on Tuscany Region (Central Italy). The first method concerns with the hierarchical approach on three levels: the studied area is divided into homogeneous regions and sub-regions, then the statistical homogeneity within the regions is verified through several homogeneity tests. Furthermore, the Two-Component Extreme Value (TCEV) probability distribution of the extreme rainfall is considered identical within each homogeneous region unless a scale factor, i.e. the index rainfall, estimated through a multivariate model based on climatic and geomorphological characteristics.

A Generalized Additive Model (GAM) for extremes is also implemented on the studied area assuming that the observations follow a Generalized Extreme Value - GEV distribution whose locations are spatially dependent. The research has been carried out starting from a general set of 922 rain gauges (Regional Hydrological Service of Tuscany - SIR), on time series of annual maximum of daily rainfall recorded from 1916 to 2017. The application of the two methods is discussed based on the comparison between the maps of the design storm for daily duration and $2,20,50,100$ e 200 years return periods. 